Article

\title{
Carotenoids, Fatty Acid Composition and Heat Stability of Supercritical Carbon Dioxide-Extracted-Oleoresins
}

\section{Cristiano Longo, Lucia Leo and Antonella Leone *}

Unit of Lecce (ISPA-CNR), Institute of Sciences of Food Production, National Research Council, Via Prov.le Lecce-Monteroni, 73100 Lecce, Italy; E-Mails: cristianolongo@ libero.it (C.L.); lucia.leo67@yahoo.it (L.L.)

* Author to whom correspondence should be addressed; E-Mail: antonella.leone@ ispa.cnr.it; Tel.: +39-0832-422-615; Fax: +39-0832-422-620.

Received: 31 January 2012; in revised form: 13 March 2012 / Accepted: 19 March 2012 / Published: 30 March 2012

\begin{abstract}
The risk of chronic diseases has been shown to be inversely related to tomato intake and the lycopene levels in serum and tissue. Cis-isomers represent approximately $50 \%-80 \%$ of serum lycopene, while dietary lycopene maintains the isomeric ratio present in the plant sources with about $95 \%$ of all-trans-lycopene. Supercritical $\mathrm{CO}_{2}$ extraction $\left(\mathrm{S}-\mathrm{CO}_{2}\right)$ has been extensively developed to extract lycopene from tomato and tomato processing wastes, for food or pharmaceutical industries, also by using additional plant sources as co-matrices. We compared two $\mathrm{S}-\mathrm{CO}_{2}$-extracted oleoresins (from tomato and tomato/hazelnut matrices), which showed an oil-solid bi-phasic appearance, a higher cis-lycopene content, and enhanced antioxidant ability compared with the traditional solvent extracts. Heat-treating, in the range of $60-100{ }^{\circ} \mathrm{C}$, led to changes in the lycopene isomeric composition and to enhanced antioxidant activity in both types of oleoresins. The greater stability has been related to peculiar lycopene isomer composition and to the lipid environment. The results indicate these oleoresins are a good source of potentially healthful lycopene.
\end{abstract}

Keywords: tomato oleoresins; cis-, trans-lycopene; heat stability; antioxidant activity; hazelnut; supercritical- $\mathrm{CO}_{2}$ extraction; nutraceuticals 
Abbreviations: $\mathrm{S}-\mathrm{CO}_{2}$, supercritical carbon dioxide; $\mathrm{S}-\mathrm{CO}_{2} \mathrm{ExT}$, oleoresin extracted from pure tomato powder; $\mathrm{S}-\mathrm{CO}_{2} \mathrm{ExTH}$, oleoresin extracted from tomato powder added with an equal amount of dry hazelnut powder; TE, Trolox equivalents; FA, fatty acid; PUFA, polyunsaturated fatty acid.

\section{Introduction}

Lycopene is the most represented carotenoid in tomato, accounting for above $90 \%$ of the total carotenoids and it is one of the major carotenoids in the Western diet. Lycopene, an acyclic isomer of $\beta$-carotene, without provitamin-A activity, is a natural red pigment synthesized by plants and microorganisms but not by animals. It is a highly unsaturated, straight chain hydrocarbon containing 11 conjugated and two non-conjugated double bonds. Serum and tissue lycopene levels have been inversely related with the risk of chronic diseases [1,2], providing explanation for the decreased risk of several pathologies, including cancer and cardiovascular disorders, correlated with a dietary intake of tomatoes and tomato-based foods [3,4]. Although interest in lycopene was firstly focused on its antioxidant properties, their beneficial effects seem to be related also to other mechanisms such as modulation of intercellular gap junction communication [5-7], hormonal and immune system, and inflammation response [8-10].

Naturally occurring geometrical isomers of lycopene are primarily in an all-trans configuration with few exceptions. Dietary studies showed that the most available sources of ingested lycopene maintain the natural isomeric distribution ratio with about $95 \%$ in the all-trans form. However cis-isomers of lycopene represent approximately $50 \%$ of total lycopene in blood and up to $80 \%$ in prostate tissues [10]. This suggested that cis-isomers are more bioavailable than all-trans-lycopene, most likely because of the greater solubility of cis-isomers in the bile acid micelles, a shorter chain length to fit into micelles, and the lower tendency to aggregate [11,12]. Recently an "in cell" isomerization has also been hypothesized [13]. The mechanisms explaining the isomerization of all-trans to cis-lycopene isomers in vivo, and the physiological importance of cis-lycopene are not fully understood. During food processing, lycopene may isomerize to cis-isoforms with the presence of heat and/or oil, or during dehydration. Moreover, during storage and/or processing lycopene undergoes further geometrical isomerization, mainly cis- to trans retro-isomerisation [14 and citations therein]. With long heating times or temperatures above $50{ }^{\circ} \mathrm{C}$, degradation proceeds faster than isomerization, the stability of lycopene isomers decreases in the order: 5-cis > all-trans $>9$-cis $>13$-cis $>15$-cis $>$ 7-cis $>11$-cis. Starting from the all-trans-lycopene, isomerization is characterized first by the formation and then by the disappearance of the unstable 13-cis-isomer [14,15]. It is clear that isomerization and degradation are competitive and contemporaneous processes.

Therefore, tomato extracts with a stable lycopene isomer profile, which do not undergo retro-isomerization, containing no unstable cis-isomers, would be an ideal source of highly bioavailable lycopene, greatly demanded for foods and nutritional supplements. Tomato oleoresins enriched in lycopene (a mixture of flavor compounds, pigments, fats, fatty acids, and sterols usually extracted by organic solvents) are readily absorbed and act as an in vivo antioxidant, in addition they are used in foods and supplements to enhance the nutritional value, functionality, color, and flavor. Lycopene is highly requested not only by food companies but also for the feed, cosmetic and pharmaceutical industries. For these reasons there is a great interest in the use of environmentally friendly processes for 
industrial production of lycopene-containing oleoresins, able to preserve the biologic properties of the components and free of residues of potentially toxic organic solvents. As a consequence many efforts are continuously made to improve extraction methodologies in order to obtain oleoresin enriched in lycopene, possibly having an isomeric composition valuable for its stability and bioavailability, and to avoid the toxic effects of the conventionally used organic solvents.

New extraction methods able to overcome the drawbacks of the traditional methods are being studied; among them the Supercritical Fluid Extraction (SFE) is the more promising process [16]. SFE provides higher selectivity, shorter extraction time and do not use toxic organic solvents. Supercritical $\mathrm{CO}_{2}$ extraction $\left(\mathrm{S}-\mathrm{CO}_{2}\right)$ has been used to extract lipid compound from numerous plant matrices [17] and has been extensively developed in recent years to extract lycopene from tomato and tomato by-products $[18,19]$. Many studies are performed on the $\mathrm{S}-\mathrm{CO}_{2}$ extraction of lycopene, focusing on technical parameter in order to increase the rate and yield of extraction and to preserve the antioxidant activity also by adding safe co-solvents such as ethanol and vegetal oils [18,20]. Beside the use of co-solvents, the modification of the starting matrix, by adding extra-matrices useful to improve the extraction yield and the quality of the final products, may be another successful strategy. This method, however, resulted in the passage of some allergenic hazelnut proteins in the oleoresin, during the extraction [21]. In our previous studies oleoresins with higher antioxidant activity and peculiar biological properties on human cell cultures were obtained by using hazelnut [7] and grape seed [5] powders, as co-matrices.

Increasing requirements from both consumers and producers, for a better understanding of nutritional components in foods or supplements and the industrial processing influences on them, are resulting in researches focused to the analysis of biochemical features and stability of $\mathrm{S}-\mathrm{CO}_{2}$ extracted oleoresins. Few studies have been so far reported on the thermal stability and isomerization of lycopene in tomato oleoresins after the $\mathrm{S}-\mathrm{CO}_{2}$ extraction process. The aim of this study was to elucidate the physicochemical features of tomato oleoresins obtained from tomato matrices added, or not, with hazelnut powder, used as co-matrix, in $\mathrm{S}-\mathrm{CO}_{2}$ extraction process. The carotenoid composition, the thermal stability and isomerization of lycopene and its antioxidant activity in such tomato oleoresins, were investigated.

\section{Experimental Section}

\subsection{Reagents and Standards}

Methanol, ethanol, hexane, ethyl acetate, acetonitrile (HPLC grade) and acetic acid were purchased from Merck Darmstadt, Germany; lutein, $\beta$-carotene, trans-lycopene, potassium persulfate (dipotassium peroxdisulfate), 6-hydroxy-2,5,7,8-tetramethylchroman-2-carboxylic acid (Trolox) was purchased from Hoffman-La Roche. 2,20-azinobis (3-ethylben-zothiazoline-6-sulfonic acid) diammonium salt (ABTS) and FAME mix were purchased from Sigma-Aldrich.

\subsection{Plant Material, Matrices and Lycopene Extraction}

Ripe fresh tomatoes (Solanum lycopersicum L. var. ramato) grown in Apulia were purchased from a local market. Tomatoes were crushed and autoclaved for $20 \mathrm{~min}$ at $120{ }^{\circ} \mathrm{C}$, then the pulp was separated from the seeds and skins, and centrifuged at 4400× $\mathrm{g}$ (Bechman, J2-21) for $30 \mathrm{~min}$, at $4{ }^{\circ} \mathrm{C}$. 
The resulting tomato paste was dried in a vacuum drying oven (Salvis Lab, IC40) at $40{ }^{\circ} \mathrm{C}$ and the obtained dried powder (about 18 mesh), was stored under vacuum, at $-20{ }^{\circ} \mathrm{C}$, protected from light. Hazelnut (Corylus avellana L.) powder was obtained from commercial toasted hazelnut crushed by a domestic blender and immediately used as extraction matrix. Tomato powder and tomato added with hazelnut powder, in a ratio 1:1 (w/w), obtained at the CNR-ISPA lab, were used as extraction matrices in $\mathrm{S}-\mathrm{CO}_{2}$ extraction.

\subsubsection{S-CO $\mathrm{CO}_{2}$ Extractions}

The extractions with $\mathrm{S}-\mathrm{CO}_{2}$ were performed in collaboration with the company Pierre s.r.l., (Galatina, Lecce, Italy) as described in [18]. Briefly, a pilot plant equipped with an extractor maintained at a temperature between $60-70{ }^{\circ} \mathrm{C}$ and properly pressurized carbon dioxide, from 400 to 450 until the final value of 30-40 bar, were used. The extractions were run by submitting $2.0 \mathrm{~kg}$ of the tomato powder or tomato powder/ hazelnut mixture in a $1: 1(\mathrm{w} / \mathrm{w})$ ratio, prepared as above described, to a pressure of $400-450$ bar and a temperature of $60-70{ }^{\circ} \mathrm{C}$. The flow rate of $\mathrm{CO}_{2}$ was in the range of $18-20 \mathrm{~kg} \mathrm{CO}_{2} / \mathrm{h}$ and the extraction time was about $7 \mathrm{~h}$. All the extracted oleoresins, from each matrix type, was pooled and stored at $-20{ }^{\circ} \mathrm{C}$.

\subsubsection{Solvent Extraction}

The tomato powder was suspended in tetrahydrofuran (THF) in the ratio 1:100 (w/v), the sample was saturated with gaseous nitrogen and the extraction was performed at room temperature, for $20 \mathrm{~min}$, under stirring in quick fit, and under dim light. The extract was centrifuged at $4300 \times \mathrm{g}$ (Hereus, Megafuge 1.0) for $10 \mathrm{~min}$, at room temperature. The surnatant was used for the analyses.

The solvent extract and the two lycopene-enriched oleoresins obtained by $\mathrm{S}-\mathrm{CO}_{2}$ extraction from tomato matrix $\left(\mathrm{S}-\mathrm{CO}_{2} \mathrm{ExT}\right)$ and tomato plus hazelnut mixtures $\left(\mathrm{S}-\mathrm{CO}_{2} \mathrm{ExTH}\right)$ were used for qualitative and quantitative analysis of carotenoids, in vitro total antioxidant activity and evaluation of their heat stability. All below described procedures were performed by replacing air with gaseous $\mathrm{N}_{2}$ and under dim light to reduce oxidation processes.

\subsection{Treatments of Supercritical $\mathrm{CO}_{2}$-Extracted Oleoresins}

Oleoresins extracted by $\mathrm{S}_{-} \mathrm{CO}_{2}(1 \mathrm{~mL})$ were centrifuged at $9000 \times \mathrm{g}$ (Beckman, Allegra 21R) for $15 \mathrm{~min}$ at $20^{\circ} \mathrm{C}$. An oily fraction (supernatant) was separated from an insoluble paracrystalline fraction (pellet). The two fractions were weighed and characterized for qualitative and quantitative analysis of carotenoids and for the in vitro antioxidant activity.

For the evaluation of the oleoresins stability to high temperatures, the whole oleoresins were kept at $25^{\circ} \mathrm{C}, 60{ }^{\circ} \mathrm{C}, 80{ }^{\circ} \mathrm{C}$ and $100{ }^{\circ} \mathrm{C}$ for $15 \mathrm{~min}$ in a water bath. After the treatments, the oleoresins were centrifuged at $9000 \times \mathrm{g}$ for $15 \mathrm{~min}$ (Beckman, Allegra 21R) at room temperature. The oil-fraction and the paracrystalline fraction were separated, weighed and then characterized for qualitative and quantitative analysis of carotenoids and for the in vitro antioxidant activity as described below. 


\subsection{Qualitative and Quantitative Carotenoids Analysis}

Carotenoids were separated by stirring $0.1 \mathrm{~g}$ of each of the two $\mathrm{S}-\mathrm{CO}_{2}$-extracted oleoresins in $10 \mathrm{~mL}$ of hexane/acetone/ethanol $(2: 1: 1, \mathrm{v} / \mathrm{v} / \mathrm{v})$ solution, and then an equal volume of distilled water was added, followed by $5 \mathrm{~min}$ of stirring. The same solvent mixture, and 1:100 (w/v) sample/solvent ratio were used to solubilize the oil- and the insoluble fractions of the not-treated and heat-treated oleoresins. After separation of the aqueous phase from the hexane, $20 \mu \mathrm{L}$ of the hexane solution containing carotenoids were injected into the high performance liquid chromatography (HPLC) system 126 solvent module equipped with a System Gold 168 diode array detector (Beckman-Coulter, Fullerton, CA). The analysis was carried out using a reverse phase (RP) C30 column $(4.6 \mathrm{~mm} 2.5 \mathrm{~cm}$, YMC, Milford, MA). A methanol/methyl butyl ether/ethyl acetate (50:40:10) solution was used as mobile phase, at a flow rate of $1 \mathrm{~mL} / \mathrm{min}$. Carotenoid detection was achieved at a $475 \mathrm{~nm}$ wavelength. Chromatographic peaks were identified by the addition of internal standards or by comparison of the absorption spectra of unknown peaks with reference standards. Carotenoid quantification was achieved by comparison with the standard curves of lutein, $\beta$-carotene, and trans-lycopene authentic standards (Sigma).

\subsection{Lipid Determination}

Total lipids were extracted from $\mathrm{S}-\mathrm{CO}_{2}$ oleoresins as described in [5]. Briefly, $0.05 \mathrm{~g}$ of the oleoresins were stirred in $5 \mathrm{~mL}$ of hexane/methanol solution $(2: 1, \mathrm{v} / \mathrm{v})$, followed by the addition of an equal volume of water. The two phases were separated by centrifugation, and the upper lipid-containing phase was concentrated on a rotary evaporator under vacuum. Total lipids were saponified with $2 \mathrm{M}$ potassium hydroxide in methanol and re-extracted by hexane. The hexane layer was separated and analyzed by a gas chromatograph coupled to a mass spectrometer (QP5050 GCMS, Shimadzu, Kyoto, Japan) equipped with a $30 \mathrm{~m}$ DB-5MS (J\&W Scientific, Folsom, CA) capillary column $(0.25 \mathrm{~mm}$ i.d., $0.25 \mu \mathrm{m}$ film thickness) for the determination of fatty acid methyl esters (FAMEs). The oven temperature profile was as follows: $80{ }^{\circ} \mathrm{C}$ for $5 \mathrm{~min}$ raised to $100{ }^{\circ} \mathrm{C}$ at $10{ }^{\circ} \mathrm{C} / \mathrm{min}$ and then to $250{ }^{\circ} \mathrm{C}$ at $5{ }^{\circ} \mathrm{C} / \mathrm{min}$ and maintained at this temperature for $15 \mathrm{~min}$. The injector and interface temperatures were $250{ }^{\circ} \mathrm{C}$. Helium was used as carrier gas at a flow rate of $1.1 \mathrm{~mL} / \mathrm{min}$. The fatty acids were fragmented by electron impact at $70 \mathrm{eV}$, identified by a comparison of their retention time and mass spectrum with those of standard FAME, and quantified according to their percentage area by integration of the peak.

\subsection{In Vitro Antioxidant Activity Analysis}

The total antioxidant activity was determined spectrophotometrically by using the Trolox Equivalent Antioxidant Capacity (TEAC) method, as described in [5]. The samples were solubilized in tetrahydrofuran (THF) in the ratio 1:100 (w/v) and then centrifuged at $4300 \times \mathrm{g}$ (Hereus, Megafuge 1.0) for $10 \mathrm{~min}$, at room temperature. A Trolox calibration curve in a range of $2.5-30 \mu \mathrm{M}$ was prepared under the same conditions of the samples. The antioxidant capacity of the samples was calculated, on the basis of the inhibition exerted by standard Trolox concentrations at $734 \mathrm{~nm}$, inhibition time being fixed at 6 min. Results were expressed as mmoles of Trolox equivalents per gram of oleoresin or per mg of contained lycopene. 


\subsection{Analytical Quality Control}

In the HPLC separation of carotenoids, linear calibration curves were obtained for lutein $\left(0.25-20 \mu \mathrm{g} / \mathrm{mL}, R^{2}=0.9999\right)$, beta-carotene $\left(0.625-50 \mu \mathrm{g} / \mathrm{mL}, R^{2}=0.9997\right)$, lycopene $(1.25-10 \mu \mathrm{g} / \mathrm{mL}$, $\left.R^{2}=0.9997\right)$. Repeatability of the HPLC method was estimated by running a standard solution containing each compound at decreasing concentration after repeated runs. After HPLC runs, the purity of analytes was checked by matching the UV/visible spectra of each peak with those of the standards. The limit of detection was calculated as the concentration yielding a signal-to-noise ratio of 2:1. Repeatability of the GC-MS in the fatty acids analysis was evaluated both for samples and standards. Samples were prepared for the instrumental analysis and injected 3 times. The standard FAME mix (Sigma Aldrich St. Louis, MO, USA) with known amounts of fatty acids: palmitic acid (16:0), palmitoleic acid (16:1), stearic acid (18:0), oleic acid (18:1) linoleic acid (18:2), linolenic acid (18:3), was analyzed in triplicate to test the recovery. The fatty acids were identified by comparison of their retention time and mass spectrum with those of standards, and quantified according to their percentage area by integration of the peaks. Precision of the TEAC results was evaluated by long-term variation (reproducibility) over a period of three months. This within laboratory reproducibility (day-to-day precision) was studied by conducting the whole method from sample extraction to spectrophotometry analysis in different weeks. The SDs were in the range $0.5-12 \%$ for TEAC. Quantification based on Trolox calibration curve, a good linearity with $\mathrm{R}^{2}$ values about 0.97 was obtained. Sample was extracted and analyzed each time in triplicate.

\subsection{Statistical Analysis}

When indicated, comparisons between mean values from control and treated samples were carried out with the two-tailed unpaired Student's $t$ test and a one-way analysis of variance (ANOVA). A value of $p<0.05$ was considered to be significant.

\section{Results and Discussion}

\subsection{Tomato Oleoresins}

Figure 1 shows the two oleoresins obtained by $\mathrm{S}-\mathrm{CO}_{2}$ extraction from either, pure tomato powder $\left(\mathrm{S}-\mathrm{CO}_{2} \mathrm{ExT}\right)$ or from tomato powder added with an equal amount of dry hazelnut powder $\left(\mathrm{S}_{-} \mathrm{CO}_{2} \mathrm{ExTH}\right)$. Hazelnut powder was used as co-matrix, in order to improve the extractability of lycopene by $\mathrm{S}-\mathrm{CO}_{2}$ methodology. The oleoresins obtained from the two plant matrices were compared for their quali-quantitative composition in carotenoids and other lipids, and for their heat stability and antioxidant activity. Both $\mathrm{S}-\mathrm{CO}_{2}$-extracted oleoresins showed a characteristic strong red color and a high carotenoid content. The oleoresins exhibited a peculiar physical status where finely granular material appeared as crystal-like dispersed in an oil phase. The biphasic appearance was evident after centrifugation of the whole oleoresins (Figure 1). 
Figure 1. (A) Supercritical- $\mathrm{CO}_{2}$-extracted oleoresins obtained from pure tomato powder $\left(\mathrm{S}-\mathrm{CO}_{2} \mathrm{ExT}\right)$ and from tomato powder added with hazelnut powder $\left(\mathrm{S}-\mathrm{CO}_{2} \mathrm{ExTH}\right)$; (B) oil- and insoluble fractions after centrifugation; (C) light microscope image of the crystal-like material scattered into the oil phase in the $\mathrm{S}-\mathrm{CO}_{2}$ extracted oleoresins (20x).
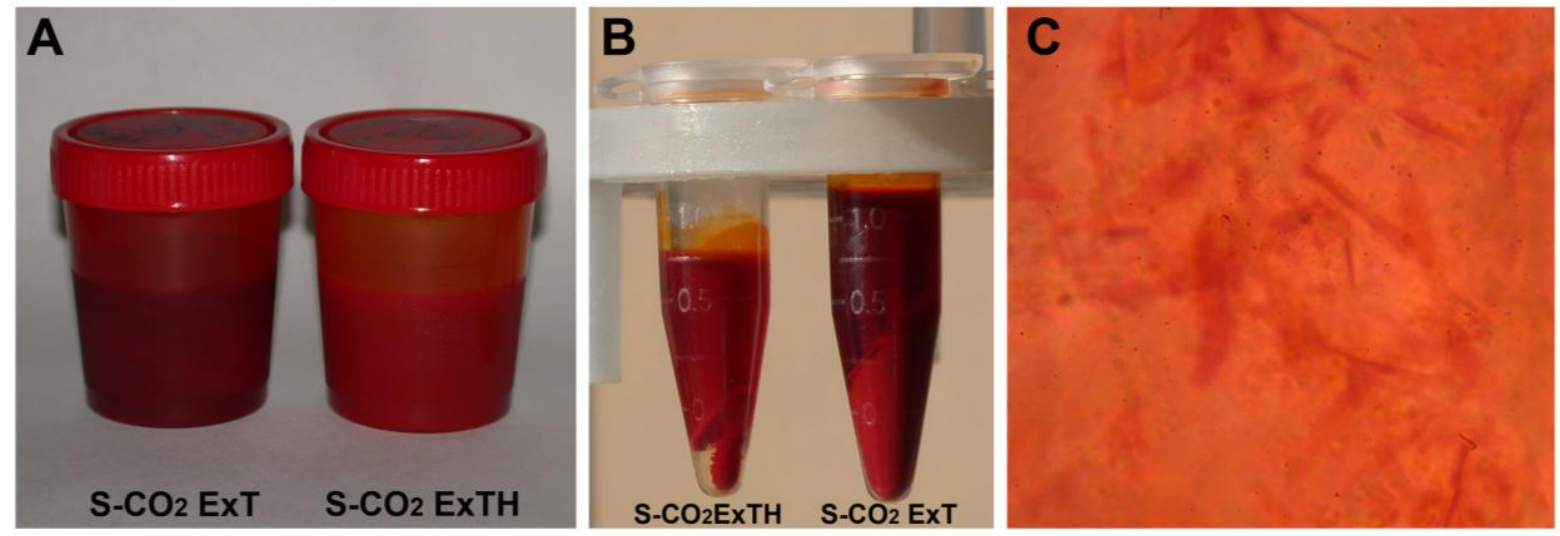

\subsection{Lycopene Content and Carotenoid Composition in Tomato Oleoresins}

Figure 2 shows the carotenoid composition detected in both the oleoresins obtained from tomato $\left(\mathrm{S}-\mathrm{CO}_{2} \mathrm{ExT}\right)$ and tomato/hazelnut $\left(\mathrm{S}-\mathrm{CO}_{2} \mathrm{ExTH}\right)$, compared with the carotenoids obtained by conventional hexane extraction from tomato powder (Solvent extract TM). The carotenoids detected in all the extracts were all-trans-lutein, $\beta$-carotene, as di-cis- $\beta$-carotene, cis- $\beta$-carotene and all-trans- $\beta$-carotene, and the lycopene isomers: 9-13-di-cis-, 13-cis-, 9-cis-, cis- and all-trans-lycopene, the last representing the main detected carotenoid (over $95 \%$ of the total carotenoids). In order to simplify the analysis, all the carotene isomers were referred as " $\beta$-carotene" and all the cis-isomers of lycopene were referred as "cis-lycopene". The hexane extraction yields a quite complete extraction of lycopene from the tomato powder. The amount of extracted lycopene was $1.19 \mathrm{mg}$ per gram of tomato powder, representing the 97.4\% of the total extracted carotenoids (Figure 2A,B). The total lycopene detected in the oleoresins extracted by $\mathrm{S}-\mathrm{CO}_{2}$ was $3.67 \mathrm{mg}$ and $1.90 \mathrm{mg}$ of lycopene per gram of tomato powder in $\mathrm{S}-\mathrm{CO}_{2} \mathrm{ExT}$ and $\mathrm{S}-\mathrm{CO}_{2} \mathrm{ExTH}$, respectively. Thus, the lycopene concentration in both the $\mathrm{S}-\mathrm{CO}_{2}$-oleoresins was higher compared to the starting tomato powder. In the $\mathrm{S}-\mathrm{CO}_{2} \mathrm{ExT}$ the total lycopene content was two times higher than in the $\mathrm{S}-\mathrm{CO}_{2} \mathrm{ExTH}$, as expected for the dilution effect caused by the hazelnut addition to the matrix. 
Figure 2. Carotenoid composition. Carotenoids and total lycopene content, expressed as mg per gram of oleoresin or tomato powder (A) or as percentage of the total carotenoids (B), in tomato powder extracted by hexane (Solvent extract), in the $\mathrm{S}-\mathrm{CO}_{2}$ oleoresin from pure tomato powder $\left(\mathrm{S}-\mathrm{CO}_{2} \mathrm{ExT}\right)$ and from tomato powder added with hazelnut powder $\left(\mathrm{S}-\mathrm{CO}_{2} \mathrm{ExTH}\right)$. Data are mean $\pm \mathrm{SD}$ of three measures from three independent samples.

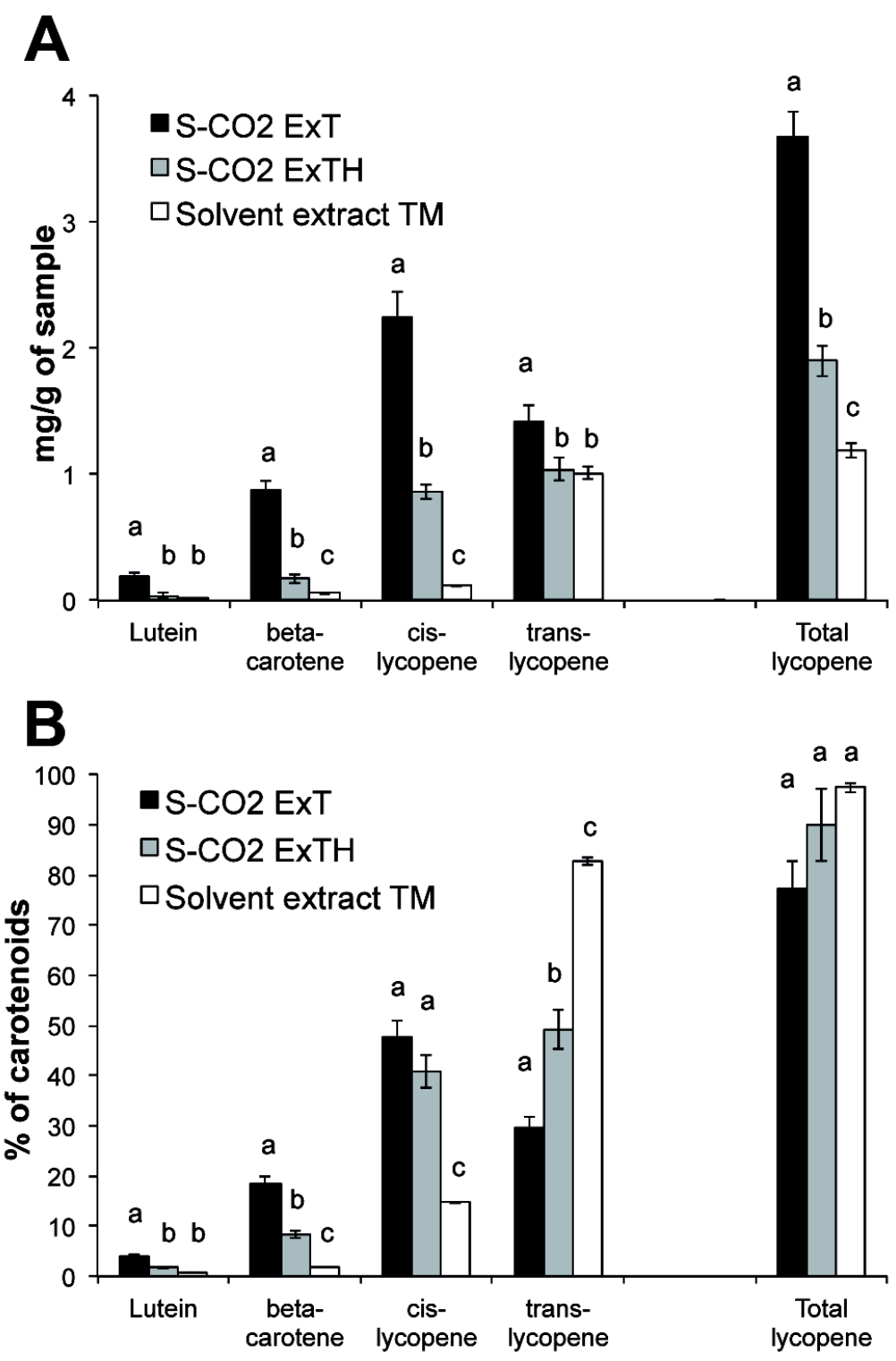

Substantial differences, only quantitative, in the carotenoid composition were observed among the different extracts. Lutein, $\beta$-carotene and lycopene were higher in the $\mathrm{S}-\mathrm{CO}_{2}$ ExT oleoresin, compared to $\mathrm{S}-\mathrm{CO}_{2} \mathrm{ExTH}$ and solvent extract. A significant difference was detected in the cis-/trans-isomers of lycopene. The solvent extract contained mainly all-trans-lycopene (cis-lycopene was $9.92 \%$ of the total carotenoids) and the cis/trans ratio was 0.18 , reflecting the ratio in the tomato powder, and very similar to the ratio in the tomato fresh fruit (0.16, data not shown). Inversely, the amount of cis-lycopene was higher in the $\mathrm{S}-\mathrm{CO}_{2}$ extracted oleoresins compared to the solvent extract, being about $47.7 \%$ and $40.7 \%$ in the $\mathrm{S}-\mathrm{CO}_{2} \mathrm{ExT}$ and $\mathrm{S}-\mathrm{CO}_{2} \mathrm{ExTH}$, respectively. In addition the cis/trans ratio was inverted in the two types of oleoresins, being 1.60 and 0.83 , in $\mathrm{S}-\mathrm{CO}_{2} \mathrm{ExT}$ and $\mathrm{S}-\mathrm{CO}_{2} \mathrm{ExTH}$, respectively. This was 
likely due to the different rate of isomerisation of the lycopene during the supercritical fluid extraction and/or to a selective cis-isomer extraction of lycopene, possibly depending from its solubility in the different extraction environment [22].

The analysis of the carotenoids was extended also to the separated oil- and insoluble-fractions of both the oleoresins, providing different HPLC profiles as showed in the Figure 3. Interestingly, it was evident a different isomeric distribution in the two fractions of both the oleoresins, where the all-trans-lycopene was mostly present in the insoluble fractions (Figure 3B,D) and the cis-isoforms were predominantly in the oil fractions (Figure 3A,C). When the insoluble material of both oleoresins, were solubilized once in hexane and stored at low temperature $\left(-20{ }^{\circ} \mathrm{C}, 16 \mathrm{~h}\right)$, a re-precipitation of a crystalline material consisting of almost pure all-trans-lycopene (Figure 3E), was observed. It can be emphasized that this appeared to be an easy method to purify all-trans-lycopene from this kind of complex oleoresins. The 15-cis-, 13-cis-, 9-cis-, 5-cis-lycopene and a number of di-cis-isomers have been identified in both fractions of the oleoresin $\mathrm{S}-\mathrm{CO}_{2} \mathrm{ExT}$ and in the oil-fraction of the oleoresin $\mathrm{S}-\mathrm{CO}_{2} \mathrm{ExTH}$.

Figure 3. Chromatographic profiles of the high performance liquid chromatography (HPLC) analysis of carotenoids. Oil-fraction (A) and insoluble-fraction (B) of the oleoresin $\mathrm{S}_{-} \mathrm{CO}_{2}$ ExT extracted from pure tomato powder. Oil-fraction $(\mathbf{C})$ and insoluble-fraction (D) of the oleoresin $\mathrm{S}-\mathrm{CO}_{2} \mathrm{ExTH}$ extracted from tomato/hazelnut powder. Insoluble paracrystalline fraction of S-CO 2 ExT oleoresin after re-precipitation in hexane (E).

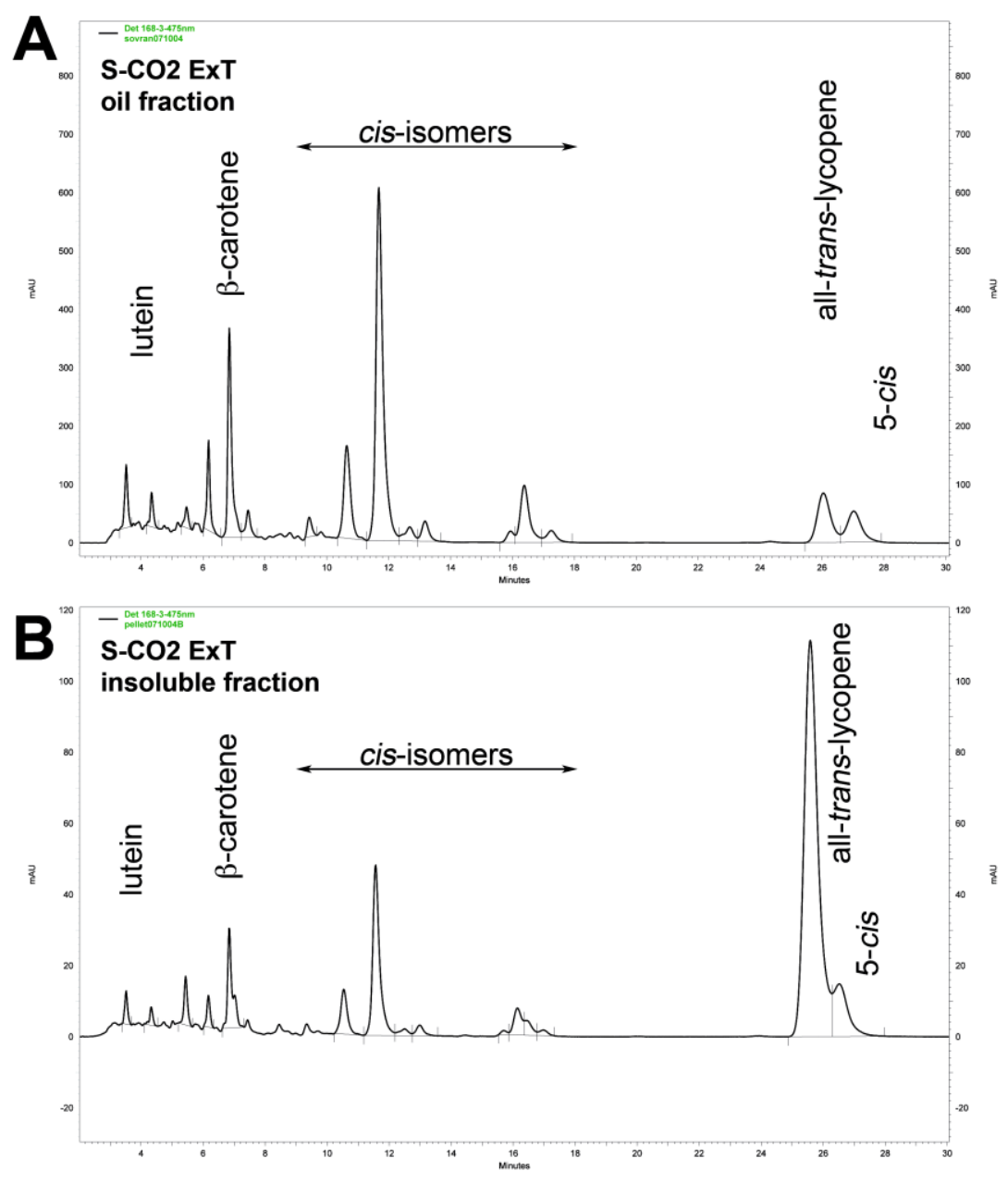


Figure 3. Cont.
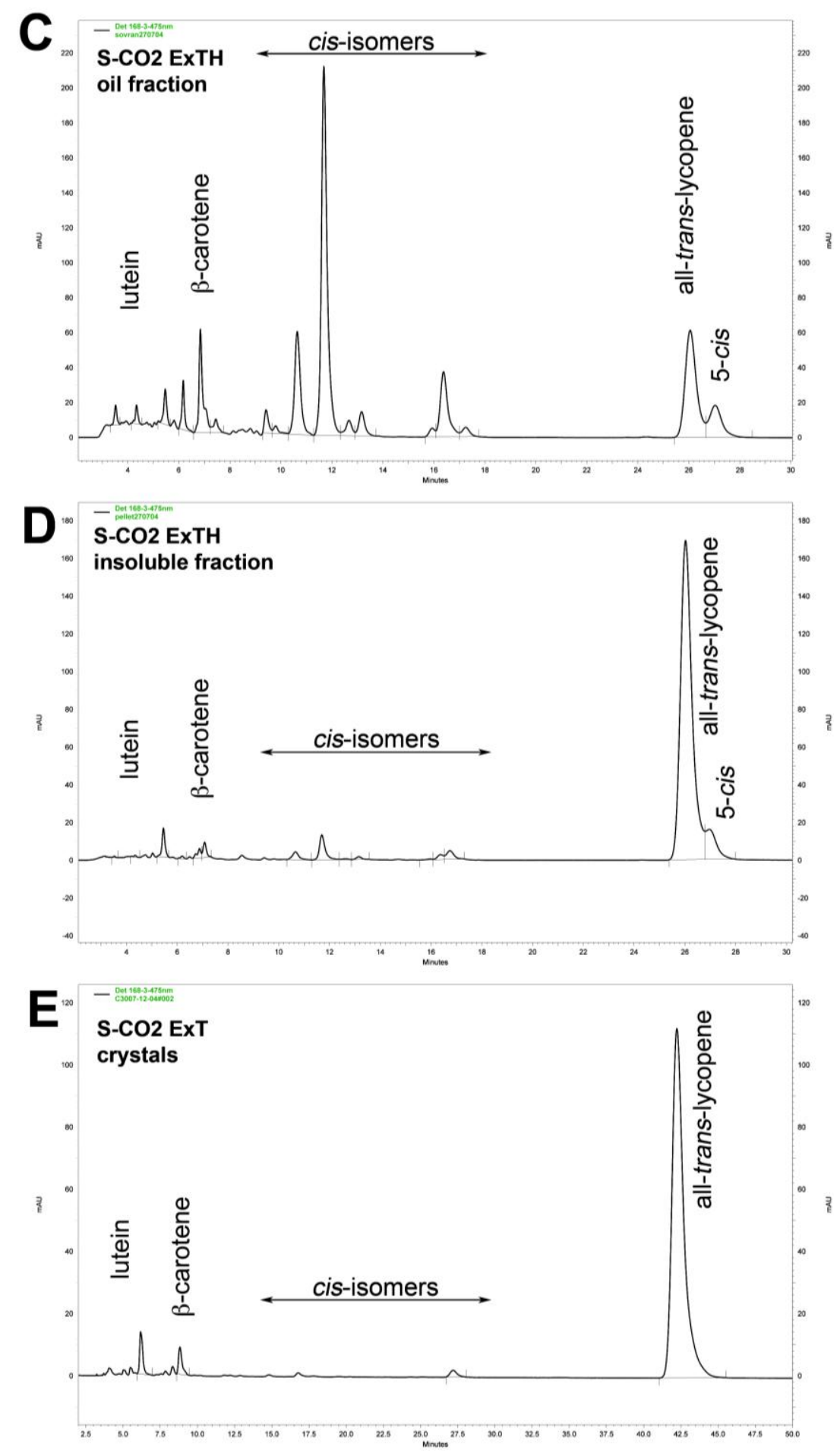

Table 1 shows the quantitative carotenoid composition detected in the oil- and insoluble fractions of the two oleoresins obtained from tomato $\left(\mathrm{S}-\mathrm{CO}_{2} \mathrm{ExT}\right)$ or tomato added with hazelnut $\left(\mathrm{S}-\mathrm{CO}_{2} \mathrm{ExTH}\right)$. The total lycopene content, as cis and trans isoforms, in the oil fraction and insoluble fraction of the $\mathrm{S}-\mathrm{CO}_{2}$ ExT oleoresin, was $306 \mathrm{mg} / 100 \mathrm{~g}$ and $582 \mathrm{mg} / 100 \mathrm{~g}$, respectively. In the oleoresin $\mathrm{S}-\mathrm{CO}_{2} \mathrm{ExTH}$ the total lycopene was $118 \mathrm{mg} / 100 \mathrm{~g}$ and $306 \mathrm{mg} / 100 \mathrm{~g}$ in the oil- and insoluble fraction, respectively. The amount of total lycopene present in tomato matrix extractable by hexane was $119 \mathrm{mg} / 100 \mathrm{~g}$ of tomato powder. Consequently, the lycopene concentration increased up to five times in the $\mathrm{S}-\mathrm{CO}_{2}$ 
extracted oleoresins. Quantitative analyses have confirmed that the insoluble-fractions were enriched in lycopene compared to the oil fractions. Again, the cis/trans-lycopene ratio was very different in the two fractions: the more stable trans-lycopene was mostly in the insoluble fractions, whereas the oil fractions contained higher amounts of cis-lycopene. The all-trans-lycopene, in the insoluble fraction of the oleoresins $\mathrm{S}-\mathrm{CO}_{2} \mathrm{ExT}$ and $\mathrm{S}-\mathrm{CO}_{2} \mathrm{ExTH}$, was $66 \%$ and $83 \%$, respectively, while in the corresponding oil fractions was $17 \%$ and $29 \%$ of the carotenoids, respectively. These results have established that the different tomato $\mathrm{S}-\mathrm{CO}_{2}$-extracted oleoresins have a complex carotenoid composition related to the physical status, with particular reference to isomeric composition of lycopene. These products may provide lycopene sources, enriched in one or in the other isomer, easily separable. The food market may also be interested in a product rich in cis-lycopene, since many studies have suggested that cis-isomers, such as 15-cis, 13-cis-, 9-cis- and 5-cis-lycopene, are present in human serum and seem more bioavailable [23-25].

\subsection{Fatty Acid Composition in Tomato Oleoresins}

The lipids present in the oleoresins were essentially triglycerides, diglycerides and monoglycerides (data not shown). Table 2 shows the lipid fatty acid percentage composition in the two oleoresins and in tomato matrix. Saturated fatty acids (FAs) as palmitic and stearic acids, monounsaturated FA as oleic acid, and polyunsaturated fatty acids (PUFA) as linoleic and linolenic acids, were detected in both oleoresins and tomato matrix. However, $\mathrm{S}-\mathrm{CO}_{2}$-extraction results in enrichment in oleic acid, which represented above $80 \%$ of the total lipids in the oleoresins. Traces of palmitoleic acid (FA derived from hazelnut) were present only in the S- $\mathrm{CO}_{2} \mathrm{ExTH}$. Only small amounts of linoleic and linolenic acids were detected in $\mathrm{S}-\mathrm{CO}_{2}$ extracted oleoresins, likely due to the susceptibility to oxidation of these PUFAs during extraction and/or storage. The lipid environment (including lipids present in the tomato matrix and vegetal co-matrix) is certainly of high importance during the extraction, affecting on the lycopene yield and on lycopene isomer composition and stability [26]. Moreover, lipids also affected the isomeric composition of lycopene, due to the different lycopene solubility in oil. In addition, lipid environment during extraction and storage may have a dual effect: lycopene protection from oxidation or, conversely, lycopene depletion triggered from the oxidized products of several easily oxidized lipids. The hazelnut-containing matrix has yielded an oleoresin with a lower lycopene concentration, but the total amount of oleoresin obtained from the same amount of matrix was notably higher (data not shown). The direct addition of the hazelnut powder was an easier and cheaper method to manage the tomato matrices. However, this method resulted in the removal of some hazelnut proteins from the hazelnut matrix and in their dragging in the oleoresin during the extraction. The extraction of proteins, their SDS-PAGE and Mass Spectrometry analyses have indicated the presence of highly allergenic protein coming from hazelnut in the $\mathrm{S}-\mathrm{CO}_{2}$-extracted oleoresins [21]. 
Table 1. Quali-quantitative analysis of carotenoids contained in the oil- and insoluble-fraction of the two S-CO $\mathrm{C}_{2}$-extracted oleoresins from pure tomato powder $\left(\mathrm{S}-\mathrm{CO}_{2} \mathrm{ExT}\right)$ and from tomato/hazelnut powder $\left(\mathrm{S}-\mathrm{CO}_{2} \mathrm{ExTH}\right)$. Values are expressed as $\mu \mathrm{g} / \mathrm{g}$ of oleoresin and as percentage of the total carotenoids. Data are mean \pm SD of three measures from three independent samples.

\begin{tabular}{|c|c|c|c|c|c|c|c|c|c|}
\hline \multirow{4}{*}{ Carotenoids } & \multicolumn{8}{|c|}{$\mathrm{S}-\mathrm{CO}_{2}$ Oleoresins } & \multirow{4}{*}{$\begin{array}{l}\text { Solvent extract } \\
\text { Tomato matrix } \\
\text { \% of carotenoids }\end{array}$} \\
\hline & \multicolumn{4}{|c|}{$\mathrm{S}-\mathrm{CO}_{2} \mathrm{ExT}^{\mathrm{a}}$} & \multicolumn{4}{|c|}{${\mathrm{S}-\mathrm{CO}_{2} \mathrm{ExTH}^{\mathrm{b}}}^{\mathrm{b}}$} & \\
\hline & \multicolumn{2}{|c|}{ Oil fraction } & \multicolumn{2}{|c|}{ Insoluble fraction } & \multicolumn{2}{|c|}{ Oil fraction } & \multicolumn{2}{|c|}{ Insoluble fraction } & \\
\hline & $\begin{array}{c}\mu \mathrm{g} / \mathrm{g} \text { of } \\
\text { oleoresin }\end{array}$ & $\begin{array}{c}\% \text { of } \\
\text { carotenoids }\end{array}$ & $\begin{array}{c}\mu \mathrm{g} / \mathrm{g} \text { of } \\
\text { oleoresin }\end{array}$ & $\begin{array}{c}\% \text { of } \\
\text { carotenoids }\end{array}$ & $\begin{array}{c}\mu \mathrm{g} / \mathrm{g} \text { of } \\
\text { oleoresin }\end{array}$ & $\begin{array}{c}\% \text { of } \\
\text { carotenoids }\end{array}$ & $\begin{array}{c}\mu \mathrm{g} / \mathrm{g} \text { of } \\
\text { oleoresin }\end{array}$ & $\begin{array}{c}\% \text { of } \\
\text { carotenoids }\end{array}$ & \\
\hline Lutein & $193( \pm 12)$ & 4.8 & $149( \pm 9)$ & 2.3 & $34( \pm 7)$ & 2.53 & $50( \pm 5)$ & 1.5 & 0.9 \\
\hline$\beta$-carotene & $801( \pm 22)$ & 19.8 & $549( \pm 19)$ & 8.4 & $145( \pm 17)$ & 10.7 & $99( \pm 7)$ & 3.1 & 4.7 \\
\hline cis-lycopene & $2353( \pm 88)$ & 58 & $1539( \pm 78)$ & 23.6 & $782( \pm 34)$ & 57.77 & $385( \pm 10)$ & 12 & 9.9 \\
\hline trans-lycopene & $706( \pm 18)$ & 17.4 & $4277( \pm 120)$ & 65.7 & $392( \pm 10)$ & 28.99 & $2677( \pm 71)$ & 83.4 & 84.5 \\
\hline Total lycopene & 3060 & 75.5 & 5816 & 89.3 & 1175 & 86.77 & 3062 & 95.4 & 94.4 \\
\hline Total carotenoids & 4056 & 100 & 6515 & 100 & 1354 & 100 & 3211 & 100 & 100 \\
\hline $\begin{array}{l}\text { Lycopene } \\
(\mathrm{mg} / 100 \mathrm{~g} \text { of oleoresin) }\end{array}$ & \multicolumn{2}{|c|}{306} & \multicolumn{2}{|c|}{581.6} & \multicolumn{2}{|c|}{117.5} & \multicolumn{2}{|c|}{306.2} & 119 \\
\hline
\end{tabular}

${ }^{\mathrm{a}}$ Oleoresin extracted by supercritical $\mathrm{CO}_{2}$ from tomato matrix; ${ }^{\mathrm{b}}$ Oleoresin extracted by supercritical $\mathrm{CO}_{2}$ from tomato/hazelnut matrix. 
Table 2. Percentage of fatty acids of lipid fraction extracted from dried tomato powder and supercritical $\mathrm{CO}_{2}$ extracted oleoresins, from tomato and tomato/hazelnut matrices. Values are expressed as percentage of the total lipids. Data are mean \pm SD of four measures from three independent samples.

\begin{tabular}{|c|c|c|c|}
\hline \multirow{2}{*}{ Fatty acids } & \multirow{2}{*}{ Tomato powder } & \multicolumn{2}{|c|}{ S-CO ${ }_{2}$-Extracted-Oleoresins } \\
\hline & & $\mathrm{S}-\mathrm{CO}_{2} \mathrm{ExT}^{\mathrm{a}}$ & $\mathrm{S}-\mathrm{CO}_{2}$ ExTH $^{\mathrm{b}}$ \\
\hline \multicolumn{4}{|c|}{ Percentage $(\%)$} \\
\hline Palmitic acid (16:0) & $23.77(1.88)$ & $5.59(0.32)$ & $5.24(0.22)$ \\
\hline Palmitoleic acid (16:1) & n.d. ${ }^{\mathrm{c}}$ & n.d. ${ }^{\mathrm{c}}$ & $0.12(0.01)$ \\
\hline Stearic acid (18:0) & $2.98(0.05)$ & $2.61(0.05)$ & $2.55(0.04)$ \\
\hline Oleic acid $(18: 1)$ & $4.22(0.98)$ & $80.46(2.59)$ & $83.04(3.03)$ \\
\hline Linoleic acid (18:2) & $52.59(1.78)$ & $9.33(0.77)$ & $8.9(0.81)$ \\
\hline Linolenic acid (18:3) & $7.38(0.57)$ & $0.71(0.03)$ & $0.15(0.01)$ \\
\hline Others ${ }^{\mathrm{d}}$ & $9.06(0.2)$ & $1.3(0.01)$ & n.d. ${ }^{c}$ \\
\hline
\end{tabular}

\subsection{Antioxidant Activity of Total and of Oil- and Insoluble-Fractions}

Figure 4 shows the antioxidant activity measured in the two oleoresins, as total suspensions and as oil- and insoluble-fraction. Both the $\mathrm{S}-\mathrm{CO}_{2}$-extracted oleoresins exhibited higher antioxidant activity, per gram of sample, compared to the hexane extract (Figure 4A). Antioxidant activity values were three times higher in the S-CO 2 ExTH $(19.6 \mathrm{mmol} \mathrm{TE} / \mathrm{g})$, and five times higher in the S-CO${ }_{2}$ ExT (34.7 mmol TE/g) compared with the solvent extract $(7.1 \mathrm{mmol} \mathrm{TE} / \mathrm{g})$. A large part of the antioxidant activity was in the insoluble fractions, which showed identical activity in both oleoresins, when expressed per gram of extract (about $33 \mathrm{mmol} \mathrm{TE} / \mathrm{g}$ ) (Figure 4B). The oil-fraction of the tomato oleoresin $\left(\mathrm{S}-\mathrm{CO}_{2} \mathrm{ExT}\right)$, showed a significantly higher activity compared to the oil fraction of the oleoresin obtained from tomato/hazelnut matrix (40.7 mmol TE/g and $18.6 \mathrm{mmol} \mathrm{TE} / \mathrm{g}$, respectively). Since the major antioxidant component of oleoresin was lycopene, and because its concentration was different in the different samples, the values of antioxidant activity were expressed per mg of contained lycopene, as shown in Figure 4C,D. No significant differences between the antioxidant activities of the two $\mathrm{S}-\mathrm{CO}_{2}$-extracted oleoresins, as total suspensions, were found $(10.3$ and $9.5 \mathrm{mmol} \mathrm{TE} / \mathrm{mg}$ of lycopene, respectively). The values of antioxidant activity were really higher compared to that of the solvent extract of the tomato matrix ( $0.9 \mathrm{mmol} \mathrm{TE} / \mathrm{mg}$ of lycopene) and to that measured in the standard all-trans-lycopene from Sigma (2.8 $\mathrm{mmol} \mathrm{TE} / \mathrm{mg}$ lycopene) in the same experimental conditions. Besides, the analysis on the separate oil- and insoluble-fractions showed that the lycopene in the oil fractions had higher antioxidant activity compared with the lycopene present in the insoluble fractions. As well, the difference between the oil-soluble lycopene in the two oleoresins was not significant (15.5 and $13.3 \mathrm{mmol} \mathrm{TE} / \mathrm{mg}$ of lycopene, respectively). The major differences were detected in the insoluble fraction, where the antioxidant activity of lycopene in $\mathrm{S}-\mathrm{CO}_{2} \mathrm{ExTH}$ was twice higher than in $\mathrm{S}-\mathrm{CO}_{2}$ ExT (10.8 and $5.3 \mu \mathrm{mol} \mathrm{TE} / \mathrm{mg}$ lycopene, respectively). Likely, the antioxidant ability was mostly related to the amount of cis-isomers of lycopene. Indeed, cis-lycopene isoforms were predominant in the oil-fractions of both oleoresins (about $77 \%$ and $67 \%$ of total lycopene in $\mathrm{S}-\mathrm{CO}_{2} \mathrm{ExT}$ 
and $\mathrm{S}-\mathrm{CO}_{2} \mathrm{ExTH}$, respectively) compared to the insoluble fractions (26\% and $13 \%$, respectively) as showed in Table 2. However, the differences in lycopene antioxidant performances seemed to be not merely determined from its chemical conformation. Indeed, the sample extracted by solvent, which contains cis-lycopene, showed yet a low antioxidant activity, similarly the all-trans-lycopene standard solubilized in hexane or THF showed very low antioxidant ability $(2.8 \mu \mathrm{mol} \mathrm{TE} / \mathrm{mg}$ of lycopene $)$. It can be inferred that the difference in the lycopene antioxidant ability was not only due to its isomeric status but also to the physicochemical environment. In the oleoresins, the presence of other lipophilic antioxidants could stabilize and/or protect the contained lycopene. On the other hand, should be noted that certain lipids highly susceptible to oxidation, like PUFAs, can be oxidized forming highly reactive radicals, resulting in antioxidant depletion. In the oleoresin obtained from tomato/hazelnut matrix, for instance, the antioxidant tocopherols, highly concentrated in hazelnut [27], may exert a protective mechanism to prevent PUFA and lycopene from being peroxidised.

Figure 4. Antioxidant activity in the total extracts, oil- and insoluble-fractions of the $\mathrm{S}-\mathrm{CO}_{2}$ extracted oleoresins. Antioxidant activity was expressed as mmol of trolox equivalent (TE) per gram of sample $(\mathbf{A}, \mathbf{B})$ or per mg of contained lycopene $(\mathbf{C , D}) . \mathrm{S}-\mathrm{CO}_{2}$ ExT: oleoresin extracted by $\mathrm{S}-\mathrm{CO}_{2}$ from pure tomato powder; $\mathrm{S}-\mathrm{CO}_{2} \mathrm{ExTH}$ : oleoresin extracted by $\mathrm{S}-\mathrm{CO}_{2}$ from tomato/hazelnut powder; Solvent extract: tomato powder extracted by hexane. Data are mean \pm SD of three measures from three independent samples.
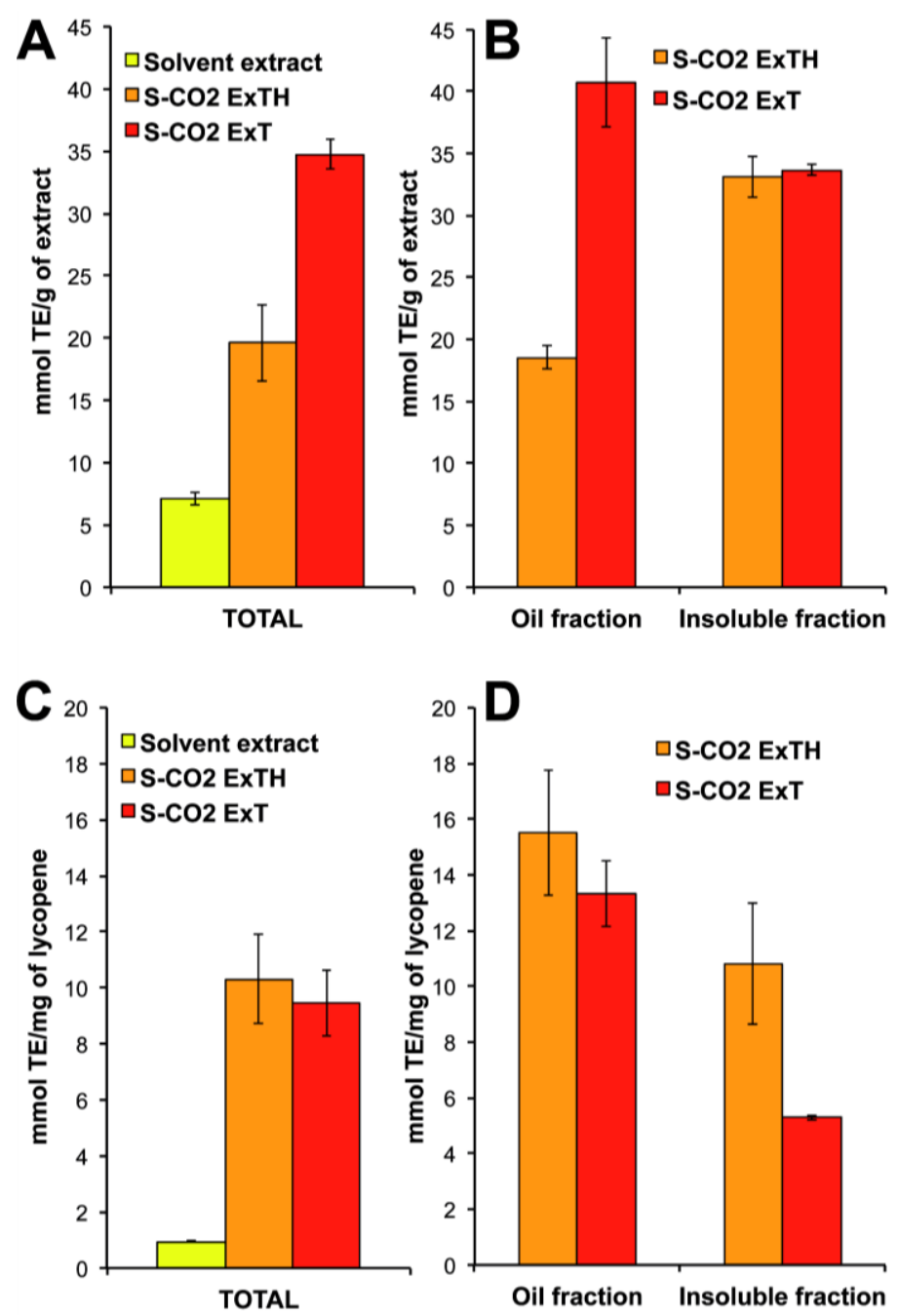


\subsection{Effect of Temperature on Carotenoid Composition of Oleoresins}

The heat stability of oleoresins, and oleoresin fractions, were assessed by thermal treating of the two whole oleoresins, in the temperature range $25-100{ }^{\circ} \mathrm{C}$. The isomeric composition and the antioxidant activity have been evaluated in both, oil- and insoluble fractions, separated after heat treatments. The total lycopene content detected in both the oleoresins, as whole (Figure 5A,B grey bars), did not seem influenced by the temperature at $60{ }^{\circ} \mathrm{C}$, but the heating at $80{ }^{\circ} \mathrm{C}$ and $100{ }^{\circ} \mathrm{C}$ induced a decreasing of the detected total lycopene, as compared to non-heated $\left(25^{\circ} \mathrm{C}\right)$ samples. In the oil fractions (Figure 5A,B white bars) no changes $\left(\mathrm{S}-\mathrm{CO}_{2} \mathrm{ExTH}\right)$ or a weak decrease $\left(\mathrm{S}-\mathrm{CO}_{2} \mathrm{ExT}\right)$ at $80{ }^{\circ} \mathrm{C}$ and $100{ }^{\circ} \mathrm{C}$ in lycopene content was detected. Changes in lycopene content, instead, were detected in the insoluble fractions of both oleoresins. In S- $\mathrm{CO}_{2} \mathrm{ExT}$, the detected lycopene resulted in a weakly but significant decrease when heated at $60{ }^{\circ} \mathrm{C}, 80{ }^{\circ} \mathrm{C}$ and $100{ }^{\circ} \mathrm{C}$, as compared to not heated $\left(25{ }^{\circ} \mathrm{C}\right)$ samples. (Figure 5A, dark bars). Conversely, a steady and significant increase of the total lycopene, at $60{ }^{\circ} \mathrm{C}$, $80{ }^{\circ} \mathrm{C}$ and $100{ }^{\circ} \mathrm{C}$, as compared to the sample kept at $25{ }^{\circ} \mathrm{C}$, was evident in the insoluble fraction of the oleoresin $\mathrm{ExCO}_{2} \mathrm{TH}$ (Figure 5B, dark bars). In the oleoresin obtained from tomato/hazelnut matrix, the increase of lycopene content, which gradually occurs parallel with the increased of temperature, was likely due to the increased solubility of the insoluble crystalline-like lycopene. The oleoresin $\operatorname{ExCO}_{2} \mathrm{~T}$ undergoes rather to a depletion of lycopene during oleoresin heating, likely due to a lycopene degradation caused of the absence of a protective lipidic environment.

Figure 5. Effect of temperature on lycopene content in the oil and insoluble oleoresin fractions. (A) S-CO $\mathrm{CO}_{2} \mathrm{ExT}$, oleoresin extracted from pure tomato powder; (B) S- $\mathrm{CO}_{2} \mathrm{ExTH}$, oleoresin extracted from tomato/hazelnut powder. Data are mean \pm SD of three measures from three independent samples.
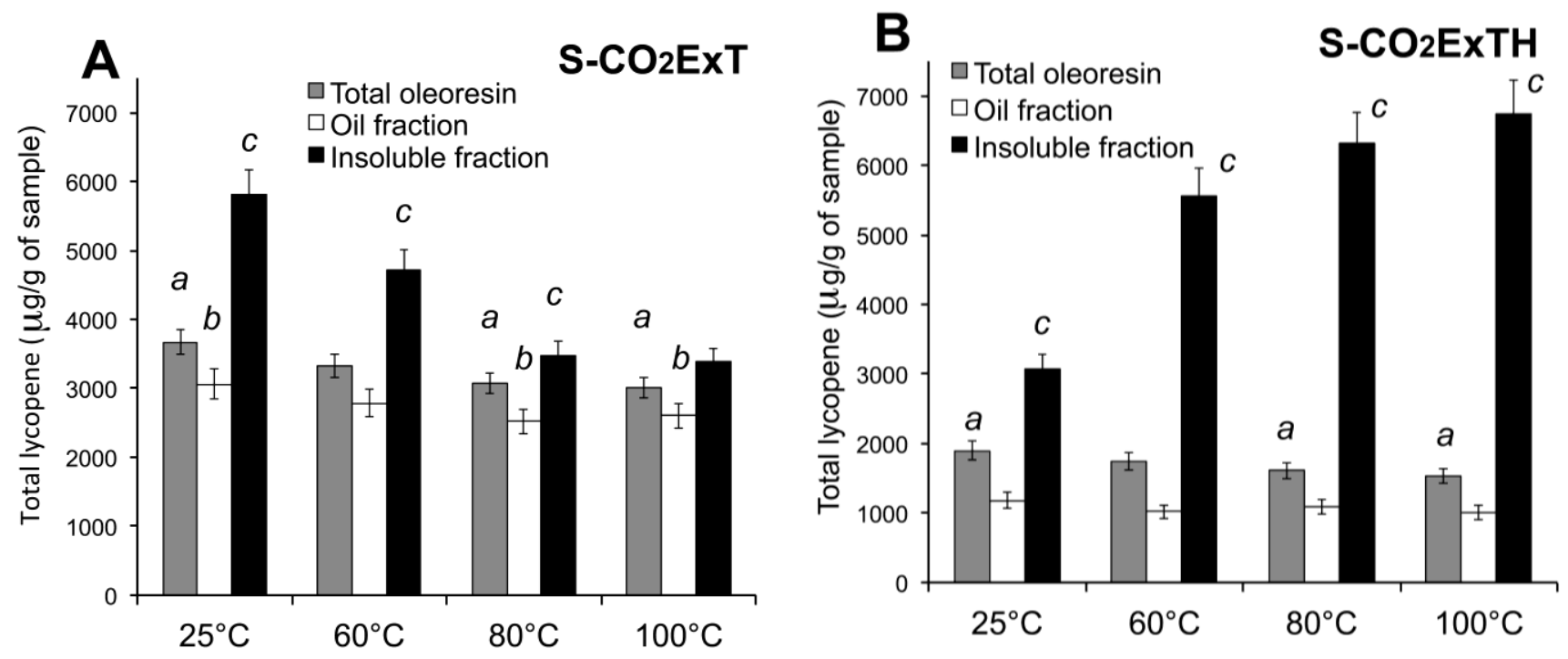

Lycopene is highly susceptible to oxidative degradation because of its highly conjugated polyenic structure. The trans forms of carotenoids are reported to be thermodynamically more stable than the cis forms. Anguelova and Warthesen [28] reported that during storage of tomato powder at $75-100{ }^{\circ} \mathrm{C}$, several cis-isomers of lycopene were formed from all-trans lycopene. Temperature and time dependent 
isomerization of all-trans lycopene to cis-isoforms was reported in different tomato oleoresins [29]. Cis-lycopene isoforms in oleoresins would be more reactive compared with the oleoresins containing the more stable all-trans-lycopene. Cis-isoforms may undergo different degradation and isomerization mechanisms than the all-trans lycopene. All-trans lycopene was reported to be more stable in safflower oil or olive oil compared to oil-in-water emulsion [26, 30]. It was also showed that lycopene in oleoresin degrades predominantly through oxidation below $50{ }^{\circ} \mathrm{C}$, and through isomerization at $75-100{ }^{\circ} \mathrm{C}$ [29]. In any case the autoxidation of either, the all-trans or cis isomer intermediates, was likely the major pathway for lycopene degradation. Thus, the different rate of lycopene degradation in different oleoresins may depend from the other components present in the oil phase of oleoresins, protective antioxidant (such as tocopherols) or high temperature generated free radicals of FAs, which can affect the lycopene degradation. Figure 6 shows the carotenoid composition, expressed as $\mu \mathrm{g} / \mathrm{g}$ of sample and as percentage of the total carotenoids, of the two fractions of both oleoresins, subjected to $25{ }^{\circ} \mathrm{C}, 60{ }^{\circ} \mathrm{C}, 80{ }^{\circ} \mathrm{C}$ and $100{ }^{\circ} \mathrm{C}$. Lutein, $\beta$-carotene and cis- and trans-lycopene, were always detected in all samples. In order to simplify the analysis, all the cis-isomers of lycopene were considered together. The results showed that heating treatments induced not significant changes in the lutein and $\beta$-carotene content, while a modification of the lycopene isomeric composition was observed after heating. In detail, in the oil fraction of both the oleoresins, the heat treatments in the range from $60{ }^{\circ} \mathrm{C}$ to $100{ }^{\circ} \mathrm{C}$ induced a decrease of cis-isoforms of lycopene and an increase of all-trans-lycopene. This shift of the lycopene isomeric composition is similar in the two oleoresins and occurred at significant extent between 60 and $80{ }^{\circ} \mathrm{C}$ (Figure 6A,B,E,F). As a result a decrease of the ratio cis/trans-lycopene related to the increasing of temperature was observed.

Figure 6. Effect of temperature on the carotenoid composition. Oil fractions $(\mathbf{A}, \mathbf{B}, \mathbf{E}, \mathbf{F})$ and insoluble fractions $(\mathbf{C}, \mathbf{D}, \mathbf{G}, \mathbf{H})$ of the oleoresin $\mathrm{S}-\mathrm{CO}_{2} \mathrm{ExT}$, extracted from pure tomato powder $(\mathbf{A}, \mathbf{B}, \mathbf{C}, \mathbf{D})$ and of the oleoresin $\mathrm{S}-\mathrm{CO}_{2} \mathrm{ExTH}$ extracted from tomato/hazelnut powder $(\mathbf{E}, \mathbf{F}, \mathbf{G}, \mathbf{H})$. Values are expressed as $\mathrm{mg}$ per gram of sample $(\mathbf{A}, \mathbf{C}, \mathbf{E}, \mathbf{G})$ and as percentage of the total carotenoids $(\mathbf{B}, \mathbf{D}, \mathbf{F}, \mathbf{H})$. Data are mean \pm SD of three measures from three independent samples $(n=9)$.
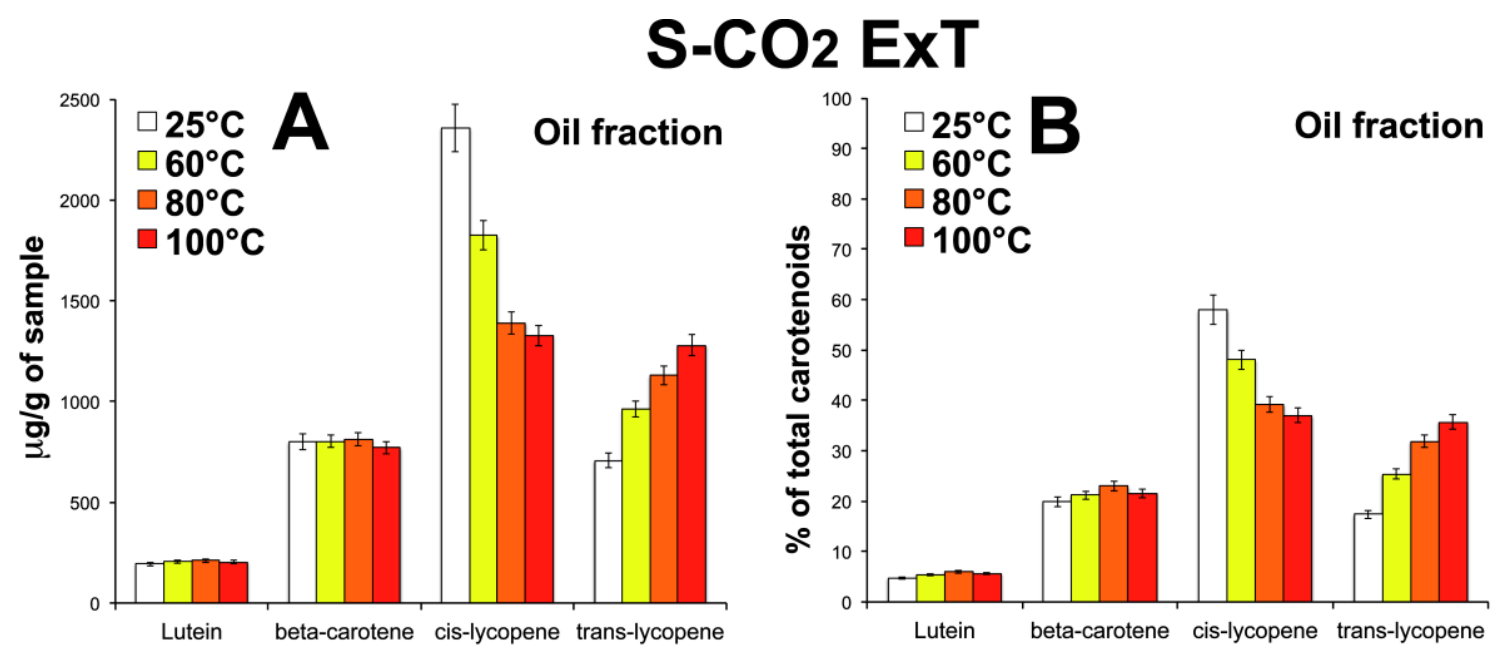
Figure 6. Cont.
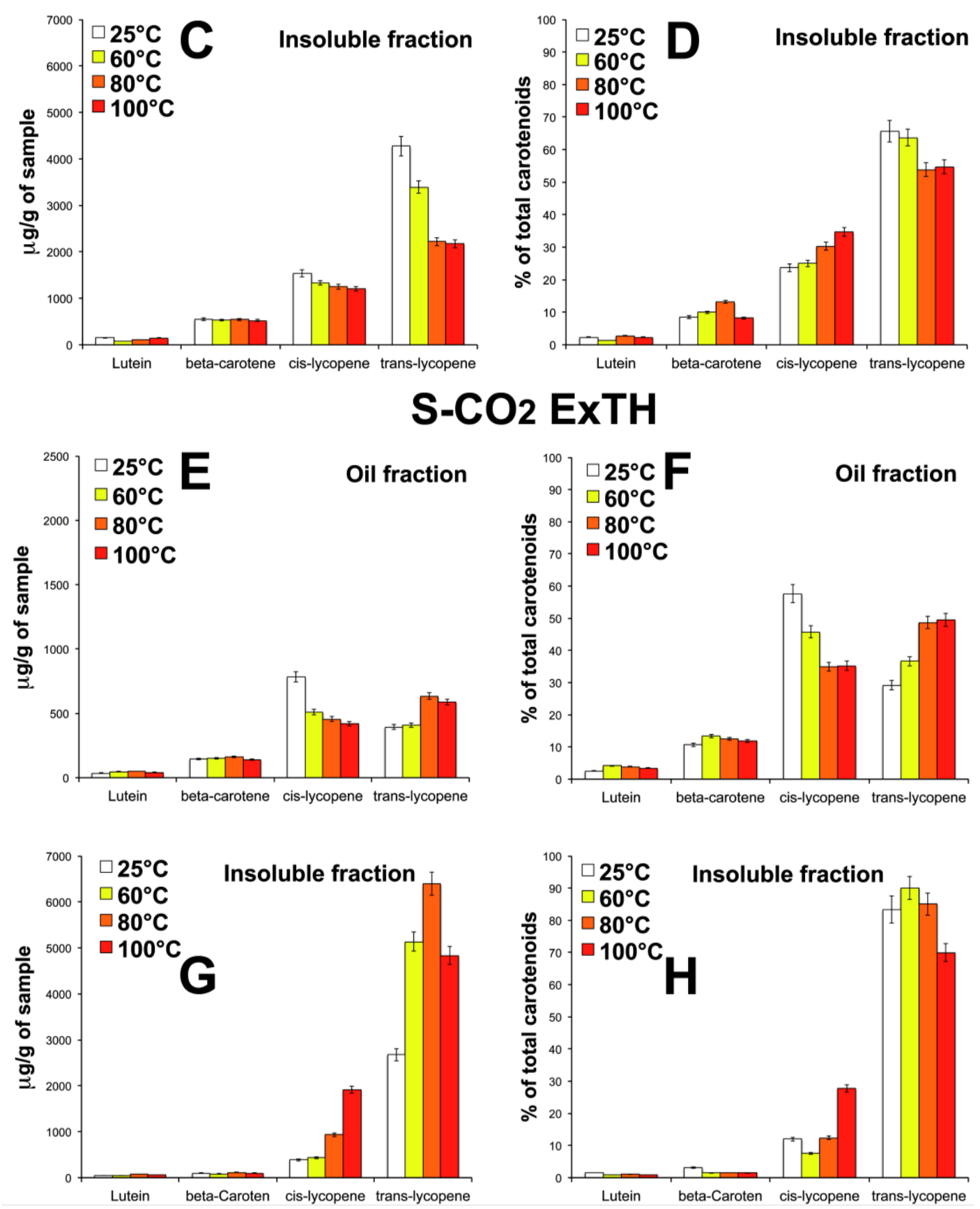

Thus, in both the oleoresins (oil fraction) we observed a temperature dependent increase in all-trans-lycopene, and a decrease in cis-lycopenes likely due to retro-isomerization cis-trans, indicating a more stable isomeric composition compared to other oleoresins produced by traditional organic solvent extraction. Cis to trans retro-isomerization, following heat-treatment of tomato oleoresins and increase in trans-isomers by heating tomato sauces were reported [14].

In the two oleoresins, the lycopene measured in the insoluble fraction showed a quite opposite response to heat treatments (Figure $6 \mathrm{C}, \mathrm{D}, \mathrm{G}, \mathrm{H}$ ). In the oleoresin $\mathrm{S}_{-} \mathrm{CO}_{2} \mathrm{ExT}$, trans and cis-isoforms of lycopene tend to decrease from $60{ }^{\circ} \mathrm{C}$ to $100{ }^{\circ} \mathrm{C}$, compared to the sample kept at $25{ }^{\circ} \mathrm{C}$. When the data were considered as percentage of the total carotenoids, it was evident that the ratio cis/trans-lycopene increased with the increasing of temperature, the crucial temperature being $80{ }^{\circ} \mathrm{C}$ (Figure 6D). This 
seems to confirm that, in $\mathrm{S}-\mathrm{CO}_{2} \mathrm{ExT}$, heating induced a degradation of the lycopene, probably through the trans to cis isomerization.

A different behavior during the heating was evident in the insoluble fraction of the oleoresin with added hazelnuts, $\mathrm{ExCO}_{2} \mathrm{TH}$ : an increase of both, cis and trans-isomers of lycopene, was observed after $60{ }^{\circ} \mathrm{C}$ and $80{ }^{\circ} \mathrm{C}$ treatments, compared to the sample at $25^{\circ} \mathrm{C}$. The further temperature increase at $100{ }^{\circ} \mathrm{C}$ induced a dropping of the trans-lycopene and a significant increase of the cis-isoforms (Figure 6G,H). This resulted in a significant change of the ratio cis/trans occurring at $100{ }^{\circ} \mathrm{C}$ confirming that the temperature of $100{ }^{\circ} \mathrm{C}$ is critical for the shift cis to trans lycopene isomerization.

Accordingly, the stability of lycopene-based products depends on their lycopene isomer profile in a complex manner. Some lycopene isomers are not stable and prone to retro-isomerization, according to the literature, 5-cis is the most stable among the predominant lycopene isomers followed by the all-trans, the 9-cis and the 13-cis. Besides, the composition of the source matrices, the temperature range and the treatment time can affect the stability of lycopene.

On the other hand, thermal isomerization of lycopene is known to improve its bioavailability from food matrices. However, to our knowledge, the bioavailability of individual lycopene isomers has not been yet investigated. It can be assumed that, as for lycopene stability, bioavailability of lycopene-based products is dependent on their lycopene isomer profile. Nevertheless, in our opinion, the assumption that only the technological processing affecting the isomeric profile can modulate the stability and bioavailability of lycopene-based products [14] is not obvious. The extreme variability in the physicochemical setting of the different varieties of oleoresins, with particular attention to the lipid environment, requires specific studies for each specific product and each processing procedure.

\subsection{Effect of Temperature on Antioxidant Activity of Oleoresins}

Figure 7 shows the effect of the heat-treatments on the antioxidant activity of the two oleoresins, $\mathrm{ExCO}_{2} \mathrm{~T}$ and $\mathrm{ExCO}_{2} \mathrm{TH}$ as whole (Total), and as oil- and insoluble-fractions. As overall trend, it was observed that the antioxidant activity of both the oleoresins increased with the increase of the temperature, whereas the solvent extract lost almost completely its antioxidant activity at temperature above $60{ }^{\circ} \mathrm{C}$ (data not shown). In detail, the oil fraction of the oleoresins $\mathrm{S}-\mathrm{CO}_{2} \mathrm{ExT}$ showed no significant changes of its antioxidant activity when submitted to heat treatments $\left(60{ }^{\circ} \mathrm{C}, 80{ }^{\circ} \mathrm{C}\right.$ and $100{ }^{\circ} \mathrm{C}$ ) compared to the sample at $25{ }^{\circ} \mathrm{C}$. Instead, the insoluble fraction increased significantly its antioxidant activity from $33 \mathrm{mmol} \mathrm{TE} / \mathrm{g}$ of sample to a value around $55 \mathrm{mmol} \mathrm{TE} / \mathrm{g}$ after heating at $60{ }^{\circ} \mathrm{C}, 80^{\circ} \mathrm{C}$ and $100{ }^{\circ} \mathrm{C}$ with no significant differences among the three temperatures (Figure 7A). This result has been confirmed by referring the antioxidant activity values per $\mathrm{mg}$ of contained lycopene (Figure 7B). The whole oleoresin and oil fraction of the $\mathrm{S}-\mathrm{CO}_{2} \mathrm{ExTH}$ (with hazelnut components), showed an increase of the antioxidant ability after the treatment at $80{ }^{\circ} \mathrm{C}$, as compared to the $25{ }^{\circ} \mathrm{C}$ treated samples, and a dropping at $100{ }^{\circ} \mathrm{C}$. This was confirmed by evaluating the antioxidant activity per $\mathrm{mg}$ of contained lycopene. Interestingly, the insoluble fraction of $\mathrm{S}-\mathrm{CO}_{2} \mathrm{ExTH}$ oleoresin displayed a linear rising of antioxidant ability as the temperature increased. The $100{ }^{\circ} \mathrm{C}$ treatment induced the doubling of the antioxidant value (from about 33 to $63 \mathrm{mmol} \mathrm{TE} / \mathrm{g}$ of oleoresin) (Figure 7C). These results are independent from the increase of lycopene content after heating (Figure 7B) as confirmed when the antioxidant activity was evaluated per mg of lycopene, (Figure 7D). It can be hypothesized 
that in this oleoresin, thermal treatment increased solubility of lycopene, which is in a physicochemical environment making it also a more efficient antioxidant.

Figure 7. Effect of the temperature on antioxidant activity in the total extracts, oil- and insoluble-fractions of the $\mathrm{S}-\mathrm{CO}_{2}$ extracted oleoresins. Antioxidant activity was expressed as mmol of trolox equivalent (TE) per gram of sample (A,C) or per $\mathrm{mg}$ of contained lycopene (B,D). S-CO $\mathrm{CO}_{2}$ ExT: oleoresin extracted by $\mathrm{S}-\mathrm{CO}_{2}$ from pure tomato powder; $\mathrm{S}-\mathrm{CO}_{2} \mathrm{ExTH}$ : oleoresin extracted by $\mathrm{S}-\mathrm{CO}_{2}$ from tomato powder added with hazelnut powder. Data are mean \pm SD of three measures from three independent samples.

\section{$\mathrm{S}-\mathrm{CO}_{2} \mathrm{ExT}$}
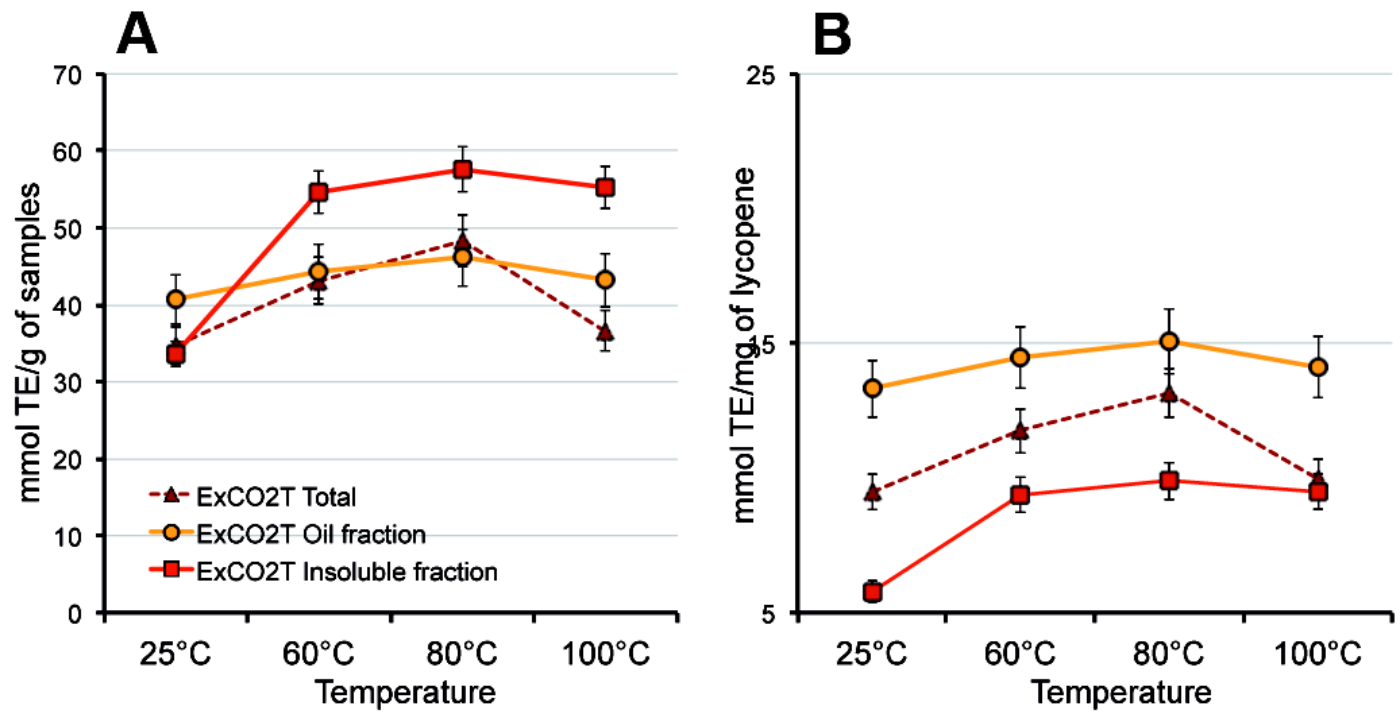

$\mathrm{S}-\mathrm{CO}_{2} \mathrm{ExTH}$
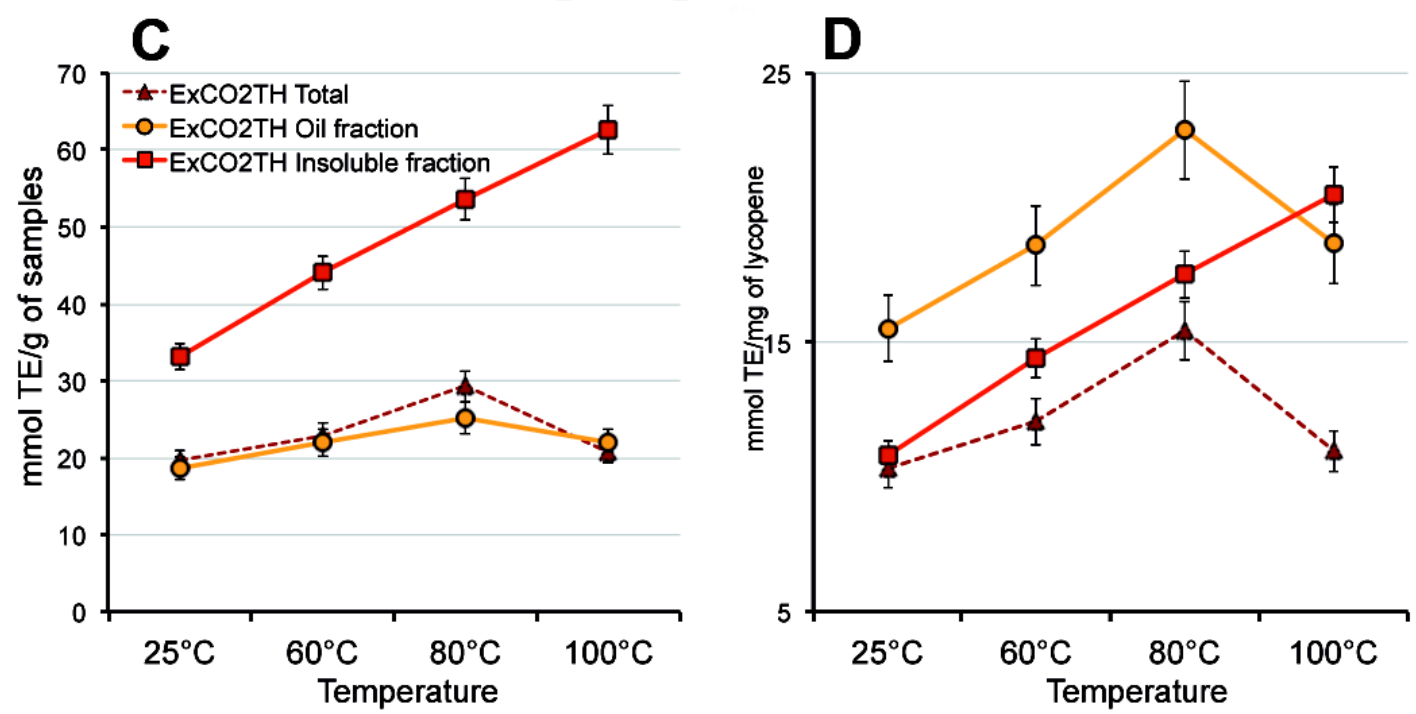

\section{Conclusions}

This study presents data on thermal stability and antioxidant activity of oleoresins extracted by $\mathrm{S}-\mathrm{CO}_{2}$ methodology, and on the analysis of the geometrical isomers of lycopene. The considered oleoresins, S- $\mathrm{CO}_{2}$ ExT and S-CO${ }_{2} \mathrm{ExTH}$, showed a peculiar bi-phasic oil-solid appearance, and an 
unique isomeric composition, with higher cis-lycopene content, enhanced antioxidant ability and thermal performances, compared with traditional solvent extracts. These results indicated a putatively more bioavailable lycopene in the $\mathrm{S}-\mathrm{CO}_{2}$ extracted oleoresins than in tomato-based foods, because of the lycopene isomeric composition more similar to that found in the human serum. The complexity of behavior of chemical species in different physicochemical environments could also explain the contradictory results of the epidemiologic and biochemical studies where the lycopene source was different (pure compounds, extracts, oleoresins or tomato-based foods). In addition, our results on the biological activity on human cell cultures of $\mathrm{S}-\mathrm{CO}_{2}$ extracted oleoresins with hazelnut [7] or grape seeds [5] added to tomato matrix, demonstrated the higher bioactivity of these oleoresins compared with organic solvent extracts. Therefore, it becomes paramount to determine the geometrical configurations of major carotenoids during analyses that pertain the putative biological activity, mainly when studies on human cell cultures are performed. Information gained from this study, together with reports on biological isomer levels, allows the further consideration of the biological relevance of lycopene isomers. To date, the most commercially available lycopene extracts exhibit isomeric profiles quite similar to the starting tomato sources, whether they are derivatives or extracted by organic solvent. S- $\mathrm{CO}_{2}$ extraction, especially in presence of oleaginous seed added matrix, offers a one-step process for lycopene extraction, solubilization and formulation. Finally, the presence of potentially allergenic hazelnut proteins in the oleoresins [21] requires careful consideration. Information gained from this study will we enable to estimate of the healthy potential of processed products, obtained by innovative extraction technologies, enriched in some key antioxidants and especially in specific geometrical isomers.

\section{Acknowledgments}

Authors would like to thank Ing. Leonerdo Rescio and Pierre s.r.l., Galatina, Lecce, Italy, for the extractions by supercritical $\mathrm{CO}_{2}$.

\section{Financial Support}

This work was financially supported by "Ministero dell'Istruzione, dell'Università e della Ricerca" (MIUR) by Project 7885: "Lycopene production from tomato berries by innovative systems".

\section{Conflict of Interest}

The authors declare no conflict of interest.

\section{References}

1. Rao, A.V.; Agarwal, S. Role of antioxidant lycopene in cancer and heart disease. J. Am. Coll. Nutr. 2000, 19, 563-569.

2. Van Breemen, R.B.; Pajkovic, N. Multitargeted therapy of cancer by lycopene. Cancer Lett. 2008, 269, 339-351.

3. Agarwal, S.; Rao, A.V. Tomato lycopene and its role in human health and chronic diseases. Can. Med. Assoc. J. 2000, 163, 739-744. 
4. Canene-Adams, K.; Campbell, J.K.; Zaripheh, S.; Jeffery, E.H.; Erdman, J.W., Jr. The tomato as a functional food. J. Nutr. 2005, 135, 1226-1230.

5. Leone, A.; Zefferino, R.; Longo, C.; Leo, L.; Zacheo, G. Supercritical $\mathrm{CO}_{2}$-extracted tomato oleoresins enhance gap junction intercellular communications and recover from mercury chloride inhibition in keratinocytes. J. Agric. Food Chem. 2010, 58, 4769-4778.

6. Livny, O.; Kaplan, I.; Reifen, R.; Polak-Charcon, S.; Madar, Z.; Schwartz, B. Lycopene inhibits proliferation and enhances gap-junctional communication of KB-1 human oral tumor cells. $J$. Nutr. 2002, 132, 3754-3759.

7. Zefferino, R.; Leone, A.; Piccaluga, S.; Cincione, R.; Ambrosi, L. Mercury modulates interplay between IL-1 $\beta$, TNF- $\alpha$, and gap junctional intercellular communication in keratinocytes: mitigation by lycopene. J. Immunotoxicol. 2008, 5, 353-360.

8. Palozza, P.; Parrone, N.; Catalano, A.; Simone, R. Tomato lycopene and inflammatory cascade: basic interactions and clinical implications. Curr. Med. Chem. 2010, 17, 2547-2563.

9. Ried, K.; Fakler, P. Protective effect of lycopene on serum cholesterol and blood pressure: Meta-analyses of intervention trials. Maturitas 2011, 68, 299-310.

10. Singh, P.; Goyal, G.K. Dietary lycopene: Its properties and anticarcinogenic effects. Compr. Rev. Food Sci. Food Saf. 2008, 7, 255-270.

11. Boileau, T.W.M.; Boileau, A.C.; Erdman, J.W. Bioavailability of all-trans and cis-isomers of lycopene. Exp. Biol. Med. 2002, 227, 914-919.

12. Unlu, N.Z.; Bohn, T.; Francis, D.M.; Nagaraja, H.N.; Clinton, S.K.; Schwartz, S.J. Lycopene from heat-induced $c i s$-isomer-rich tomato sauce is more bioavailable than from all-trans-rich tomato sauce in human subjects. Br. J. Nutr. 2007, 98, 140-146.

13. Teodoro, A.J.; Perrone, D.; Martucci, R.B.; Borojevic, R. Lycopene isomerisation and storage in an in vitro model of murine hepatic stellate cells. Eur. J. Nutr. 2009, 48, 261-268.

14. Lambelet, P.; Richelle, M.; Bortlik, K.; Franceschi, F.; Giori, A.M. Improving the stability of lycopene Z-isomers in isomerised tomato extracts. Food Chem. 2009, 112, 156-161.

15. Xianquan, S.; Shi, J.; Kakuda, Y.; Yueming, J. Stability of lycopene during food processing and storage. J. Med. Food 2005, 8, 413-422.

16. Herrero, M.; Mendiola, J.A.; Cifuentes, A.; Ibáñez, E. Supercritical fluid extraction: Recent advances and applications. J. Chromatogr. A 2010, 1217, 2495-2511.

17. Shi, L.-E.; Zhang, Z.-L.; Xing, L.-Y.; Yang, D.-D.; Guo, Y.-P.; Guo, X.-F.; Zhao, L.-M.; Tang, Z.-X. Antioxidants extraction by supercritical $\mathrm{CO}_{2}$. J. Med. Plants Res. 2011, 5, 300-308.

18. Ciurlia, L.; Bleve, M.; Rescio, L. Supercritical carbon dioxide co-extraction of tomatoes (Lycopersicum esculentum L.) and hazelnuts (Corylus avellana L.): A new procedure in obtaining a source of natural lycopene. J. Superscrit. Fluids 2009, 49, 338-344.

19. Topal, U.; Sasaki, M.; Goto, M.; Hayakawa, K. Extraction of lycopene from tomato skin with supercritical carbon dioxide: Effect of operating conditions and solubility analysis. J. Agric. Food Chem. 2006, 54, 5604-5610.

20. Yi, C.; Shi, J.; Xue, S.J.; Jiang, Y.; Li, D. Effects of supercritical fluid extraction parameters on lycopene yield and antioxidant activity. Food Chem. 2009, 113, 1088-1094. 
21. Leone, A.; Conti, A. National Research Council, Institute of Food Production (CNR-ISPA), Lecce, Italy. Supercritical $\mathrm{CO}_{2}$ extraction from a tomato/hazelnut matrix results in production of oleoresin containing allergenic proteins from hazelnut. 2010; (Unpublished work).

22. Gòmez-Prieto, M.S.; Caja, M.M.; Herraiz, M.; Santa-Marìa, G. Supercritical fluid extraction of all-trans-lycopene from tomato. J. Agric. Food Chem. 2003, 51, 3-7.

23. Van Breemen, R.B.; Xu, X.; Viana, M.A.; Chen, L.; Stacewicz-Sapuntzakis, M.; Duncan, C.; Bowen, P.E.; Sharifi, R. Liquid chromatography-mass spectrometry of cis- and all-trans-lycopene in human serum and prostate tissue after dietary supplementation with tomato sauce. J. Agric. Food Chem. 2002, 50, 2214-2219.

24. Boileau, A.C.; Merchen, N.R.; Wasson, K.; Atkinson, C.A.; Erdman, J.W., Jr. Cis-lycopene is more bioavailable than trans-lycopene in vitro and in vivo in lymph cannulated ferrets. $J$. Nutr. 1999, 129, 1176-1181.

25. Wu, K.; Schwartz, S.J.; Platz, E.A.; Clinton, S.K.; Erdman, J.W., Jr.; Ferruzzi, M.G.; Willett, W.C.; Giovannucci, E.L. Variations in plasma lycopene and specific isomers over time in a cohort of US men. J. Nutr. 2003, 133, 1930-1936.

26. Colle, I.J.P.; Lemmens, L.; Tolesa, G.N.; van Buggenhout, S.; de Vleeschouwer, K.; van Loey, A.M.; Hendrickx, M.E. Lycopene degradation and isomerization kinetics during thermal processing of an olive oil/tomato emulsion. J. Agric. Food Chem. 2010, 58, 12784-12789.

27. Parcerisa, J.; Richardson, D.G.; Rafecas, M.; Codony, R.; Boatella, J. Fatty acids, tocopherol and sterol content of some hazelnut varieties (Corylus avellana L.) harvested in Oregon (USA). J. Chromatogr. A 1998, 805, 259-268.

28. Anguelova, T.; Warthesen, J. Lycopene stability in tomato powders. J. Food Sci. 2000, 65, 67-70.

29. Hackett, M.M.; Lee, J.H.; Francis, D.; Schwartz, S.J. Thermal stability and isomerization of lycopene in tomato oleoresins from different varieties. J. Food Sci. 2004, 69, 536-541.

30. Ax, K.; Mayer-Miebach, E.; Link, B.; Schuchmann, H.; Schubert, H. Stability of lycopene in oil-in-water emulsions. Eng. Life Sci. 2003, 3, 199-201.

(C) 2012 by the authors; licensee MDPI, Basel, Switzerland. This article is an open access article distributed under the terms and conditions of the Creative Commons Attribution license (http://creativecommons.org/licenses/by/3.0/). 